\title{
The Times Connotation and Ways of Realization of Horse Culture in Wuhan
}

\author{
Quan'an Gui \\ The School of Physical Education \\ Wuhan Business University \\ Wuhan, China
}

\author{
Yangzhou Xiang \\ The School of Physical Education \\ Wuhan Business University \\ Wuhan, China
}

\begin{abstract}
Through researching the literature of countries and regions owning advanced horse industry in the world, we can figure out that these places attach high attention to cultivating horse culture and creating atmosphere. It is also the long history for over one hundred years that make horse culture boom. However, Wuhan used to be the "Capital of Horse-racing", lacks dense atmosphere. The refore, this article uses literature, logical analysis and other research methods to analyze the times connotation and current situation of Wuhan's horse culture, through which we find out the realistic difficulties of cultivating it Thus, we propose suggestions, such as realizing its economization, building relevant museum and industrial park, as well as creating the cultural spirit of "Chinese Horse", in order to inherit and promote the healthy and sustainable development of Wuhan horse culture, as well as facilitate its effective development and utilization.
\end{abstract}

Keywords-horse culture; times connotation; ways of realization

In Britain, horse culture is a social activity for leisure and entertainment involved by all people. It enjoys a long history for more than three hundred years, occupying a pivotal place in British history and culture; in the United States, deeply rooted in horse industry, it affects Americans in an all-round way, making horse industry highly developed. Universities set many majors about horse, such as equine veterinary and stable management. In addition, there are courses like "horse riding" for non-professional students; in Japan, commercial horse racing pays much attention to promoting and inheriting horse culture. Representative cultural heritages include Soma Nomaoi, Soma Wild-Horse Roundup and Horohiki (Synchronized equestrian pennant display).Japan's horse culture gains further growth because they attach great importance to it; in Hong Kong, China, horse racing enjoys a long history and covers every corner of Hong Kong. It has been an indispensable part of its current development [1].

Throughout countries and regions owning advanced horse industry, it is horse culture that prospers their horse industry. Wuhan, once the "Capital of Horse-racing", used to have three Racecourse, namely Xishang, Huashang and Wanguo. However, they failed to form a dense atmosphere of "horse culture”. Today, people in Wuhan still keep it at arm's length. Few people would participate in horse racing and equestrian activity. Horse culture has yet to be universal. Under this circumstance, we must emphasize the cultivation and creation of horse culture while developing horse industry. Therefore, through learning the epoch connotation and current situation, this article figure out some problems about cultivating horse culture and propound some advice for promoting horse industry in Wuhan, so as to propel its development and utilization.

\section{Current Situation of Wuhan's Horse Culture}

\section{A. Epoch Connotation of Wuhan's Horse Culture}

Horse culture plays an irreplaceable role in horse industry. It not only promotes the horse industry in the world, especially in China. Thus, in order to develop Wuhan's horse industry, we must weigh the horse culture and establish its status and roll through learning its evolution[2].

1) Development Process

In 1902, British built "Xishang Racecourse in Hankou, Wuhan. In 1906, Liu Xinsheng, Liang Junhua and others invested in building "Huashang Racecourse". In 1924, Wang Zhifu constructed "Wanguo Racecourse" in joint venture with Wu Chunsheng and other businessmen in Hankou[3].But three racecourses were shut down for different reasons after 1949.At that time, not only Wuhan, the whole country's horse racing fell into a low ebb.

It was not until 2003 that Wuhan, the once "Capital of Horse-racing”, hosted the first racing festival, which was also called the "first racing in 54 years". So far, the horse racing interrupted for nearly 54 years developed and boosted again[4] By May 2017, "Wuhan International Horse Racing Festival" has held 14 consecutive years, which not only plays a positive role in enhancing the rapid development of economy and urban construction in Wuhan, but also increases its influence. Besides the horse racing, equestrian sports have thrived in recent years in Wuhan. There have been 13 equestrian clubs, including riding and shooting, dressage, horse archery for leisure and adolescent training.

\section{2) Practical Significance}

In countries and regions owning advanced horse industry, they attach great importance to cultivating and creating horse culture. It becomes the key factor of restricting worldwide horse industry. If the horse industry can create more social value, the horse culture can play more prominent effect. The prosperity and development of the latter can highlight the characteristic of local horse industry, which is beneficial to increase its economic and added value. 


\section{B. Current Situation of Wuhan's Horse Culture}

Oriented by speed racing, Wuhan International Horse Racing Festival is themed by "Horse" and subtly integrates horse culture with Chu culture, sports and tourism [5]. "Dream as Horse Culture Festival" has been held for four years in Wuhan Business University, the first international equestrian academy in China. It aims at connecting non-professional students with horse, so they can learn relevant knowledge, spread horse culture and inherit the spirit and tradition of the saddle club for students. More than 30 places in the three towns of Wuhan were named after horse, which contains many stories about horse.

However, the horse racing was interrupted for 54 years in Wuhan, so was the horse culture. People are unfamiliar with the racing and equestrian sports, so few people would participate in it and they show insufficient passion. Under this circumstance, problems do exist with cultivating and creating horse culture. First, it is urgent to strengthen the dissemination of horse culture. Equestrian and racing sports can develop when there are enough racing fans, while the latter needs dense atmosphere of horse culture. In Wuhan, few people actually know horse, racing and equestrian, which means we must strengthen the dissemination of horse culture. Only in this way can there be more racing fans and better development of horse industry. Secondly, the economic integration of horse culture remains low. Racecourse and equestrian sports is the carrier and platform to demonstrate and disseminate horse culture. So both economic and social benefit should be pursued. Therefore, we must act proactively while hosting horse racing and other equestrian sports, working hard to obtain supporting policy. We should come up with new methods to give full play to the unique resources and regional advantage, sparing no efforts to achieve economic integration of horse culture.

\section{Difficulties of Cultivating Horse Culture in WuHan}

\section{A. Bottleneck of Concept}

\section{1) Outdated Cultural Value of Participants}

Racing fans, the participants of horse racing and equestrian sports, are foundation of it. Foreign racing fans have a profound understanding of horse industry. They regard equestrian and racing as a massive sports involved by everyone. They would foster their children's interest in equestrian and racing. It's common to go for further study by virtue of it. However, the cultural value of racing fans in Wuhan remains low. Due to the insufficient atmosphere of horse culture, they know little about horse racing and equestrian. On the day of the "members of racing fans" held by Wuhan International Racecourse of Oriental Horse Capital, most people failed to answer the knowledge about horse racing quickly and correctly. After some inquiry, we found that there were few senior racing fans. Most "fans" watch horse racing less than three times and do it just for fun. They believe they have little to do with horse racing and equestrian.

\section{2) Outdated Cultural Value of Practitioners}

There are 12 saddle clubs in Wuhan, but the idea of some practitioners still pauses in 10 years ago. As the Chinese Horse
Racing•2017 Traditional Endurance Events was held in Dangshan, Anhui, some practitioners failed to understand the reason. Therefore, it can be seen that practitioners lack enough understanding and their cultural value remains outdated. As a practitioner, he should pay more attention to the horse industry, especially the development of horse culture. Only changing ideas and deepening the understanding of horse industry and horse culture can they promote the development of horse racing and equestrian.

\section{B. Bottleneck of Resources}

1) Shortage of Talents in Industry of Horse Culture

The foundation of horse industry lies in the cultivation and creation of horse culture. As the core and key factor, highquality personnel are the inevitable requirement of promoting Wuhan's horse industry. Thus, we must fully recognize the significant meaning of it. However, talents who master the technology and management of cultural industry lack the knowledge of horse culture, while those who have relevant knowledge lack professional skills. Therefore, as the horse industry is developing rapidly, we must attach highly importance to cultivating the personnel of the industry of horse culture. China's horse industry can catch up with the international one only if we foster a better atmosphere of horse culture through the development of the industry of horse culture.

\section{2) Tight Outlay for Building Horse Culture}

For the 14 saddle clubs in Wuhan, most of them fail to set aside for building horse culture, main reason of which is tight outlay. As for the club's growth, the insufficient atmosphere leads to limited benefit, most of which is used for horse caring and wages. When it comes to the construction and creation of horse culture, managers know little about its importance and invest much in purchasing horses and building racecourse. Some clubs even promote horse riding for entertainment. They only want to make a profit out of it, instead of building horse culture. So they have almost no provisions for it. What's more, even if the sports bureau invests money in it, the funds are in short, while building horse culture is a costly and long-term project. Thus, it will be difficult for the sports bureau to build it. In terms of the Wuhan and Hubei Equestrian Association, as a nonprofit professional organization for masses, it definitely lacks enough money.

\section{AdVICE for ReAlizing Horse Culture in WuHAN}

\section{A. Achieving the Economization of Horse Culture}

The so-called "economization of horse culture" means that horse culture enters into the labor market for exchange. The growing trends of it consist in the industrialization of horse culture. The latter one implies that, based on the material, we process the activities of horse culture and its fruits into products that can be exchanged on market. These products also need to be oriented by people's spirit demands, under the premise of keeping the characteristics and function of horse culture. Then people can communicate and consume them.

One approach to realize the economization of horse culture lies in enhancing cultural soft power. It is beneficial to elevate 
the cultural level and taste, which has already become the inner impetus to improve economic growth and development of horse industry.

\section{B. Building the Industry of Horse Culture in Wuhan}

\section{1) Constructing Horse Culture Museum}

Building interactive museum of horse culture is conducive to spread horse culture. In analogy with the Hailan Horse Culture Museum, Wuhan Horse Culture Museum can follow its structure. The collection can contain works of art related to horse, such as poetry, sculpture, painting and literature, making horse culture no less real; house of famous horses can collect rare breeds for visiting, so we can learn the breeds, their habits and feeding; people can experience the history that we shared with the horses through time-travel in experience museum. What's more, we can also experience feeding, brushing, and saddling up, riding and other activities. Through these, we can learn the knowledge and skill of how to get along with horses. Wuhan Horse Culture and History Museum will show you the charm of Wuhan by its various information, making you fall in love with horse riding and enjoy its joy.

\section{2) Creating the Industrial Park of Horse Culture}

To build a industry park, we should combine the horse riding, equestrian, horse culture, riding for leisure, reception, breeding, natural ecology, equestrian academy, themed park with other functions. Support from departments should be obtained. We can also band with the first equestrian academy, equestrian clubs in Wuhan, Hubei and Wuhan Sports Bureau and Equestrian Association, so as to build a unique industrial park of horse culture in central China. By this, we work hard to hold international events and horse forums, making more people receive professional study and train in Wuhan and enjoy the first-rated events at home and abroad.

\section{3) Forging the Cultural Spirit of "Chinese Horse"}

Invisible, untouchable and uncatchable as it is, "Spirit" can turn into material power. In Wuhan's long history, we form the spirit of "daring to be the first, striving for excellence", which is the first time Wuhan extracted urban spirit. Meanwhile, we hope that we can forge the cultural spirit of "Chinese Horse" and make it Wuhan's second urban spirit. The spirit of horse cultural is a national and creative one showing struggling, unyielding and pioneering. It delivers the positive energy of the times referring to high enthusiasm and braveness, as well as demonstrates the spirit of selfimprovement and pioneering, which is highly ornamental and appealing.

\section{CONCLUSION}

Currently, China's horse industry is still immature and the related policy and institution remain incomplete. We should facilitate the development of horse riding and equestrian sports and create consume demand by building the atmosphere of horse culture and publicizing it. Besides, we hope that associations and clubs could attach importance to supporting programs like researching and teaching of the horse culture and its foreign exchange. Thus, Wuhan can own advanced industry of horse culture constituted by horse education, research, media, art and cultural transmission. In the meantime, horse culture will become a new label for Wuhan. It means that we can expand its popularity, manifesting the charm of horse culture existing for thousands of years and rebuild the "Capital of Horse-ricing". In addition, we can make horse culture be the new synonym for Wuhan and the development of horse riding and equestrian sports be the new sources of economic growth.

\section{ACKNOWLEDGMENT}

This research was supported by the Colleges and Universities Outstanding Youth and Middle Aged Scientific and Technological Innovation Team Project of Hubei Province (No.T201628).

\section{REFERENCES}

[1] F.H. Yang, "Study on the Influence of Horse Culture on Horse Riding Industry,” Journal of Wuhan Commercial Service College, vol. 24, pp. 8-11, October 2010. (In Chinese)

[2] P. Ding, “Chinese and Wuhan Horse Culture,” Science \& Technology Information, vol. 3, pp. 429-430, January 2011. (In Chinese)

[3] C. Yang, Q.S. Hu, and M.R. Liu, "On the Construction of Management System of Sport Event Risks in China's Commercial Horse Ricing," Journal of Shanghai University of Sport, vol. 36, pp. 27-31, January 2012. (In Chinese)

[4] G. Yu and Y.J. Xia, "Study on the Promotion of Horse Ricing on Urban Cultural Construction in Wuhan," Journal of Wuhan Commercial Service College, vol. 27, pp. 5-7, February 2013. (In Chinese)

[5] D.H. Zhou and Y.Z. Xiang, “Development of Professional Skill Standard of Foreign Horse Ricing(Equestrian) and References of its Experience,” Journal of Wuhan Business University, vol. 27, pp. 19-22, June 2016. (In Chinese)

[6] Y.F. Deng and Q.X. Zeng, "Strategies for Horse Racing Industry in Hubei Province,” Journal of Wuhan Institute of Physical Education, vol. 50, pp. 44-47, January 2016. (In Chinese) 